Review Article

\title{
Chinese Herbal Extractions for Relieving Radiation Induced Lung Injury: A Systematic Review and Meta-Analysis
}

\author{
Bo Deng, ${ }^{1}$ Chao Deng, ${ }^{1,2}$ and Zhiqiang Cheng ${ }^{1}$ \\ ${ }^{1}$ Department of Oncology of Integrative Chinese and Western Medicine, China-Japan Friendship Hospital, Beijing 100029, China \\ ${ }^{2}$ Beijing University of Chinese Medicine, Beijing 100029, China \\ Correspondence should be addressed to Zhiqiang Cheng; zhiqiangcheng@163.com
}

Received 3 November 2016; Accepted 9 March 2017; Published 29 March 2017

Academic Editor: Oliver Micke

Copyright (c) 2017 Bo Deng et al. This is an open access article distributed under the Creative Commons Attribution License, which permits unrestricted use, distribution, and reproduction in any medium, provided the original work is properly cited.

\begin{abstract}
Background. Radiation induced lung injury (RILI) is one of the most common and severe side effects of thoracic radiotherapy. In this meta-analysis, the effects of Chinese herbal extractions (CHE) for preventing and treating RILI are evaluated. Methods. Randomized Controlled Trials (RCTs) from five databases were identified. Studies were evaluated and the relevant data were extracted by two authors independently. Differences were resolved by a third party. Meta-analysis was conducted using RevMan 5.0. Results. In total, 2734 participants receiving thoracic radiotherapy were included in 28 RCTs, and 16 CHE were evaluated. Meta-analysis showed that CHE intervention significantly reduced the incidence of acute radiation pneumonitis (RP) and radiation induced pulmonary fibrosis (RIPF). In CHE group, total effective rate and remission rate of RILI patients were significantly higher. Patient's quality of life (Qol) and clinical symptoms and signs were improved significantly. Inflammatory cytokines decreased, and thymus dependent lymphocytes subgroups were improved. Conclusion. CHE intervention may have clinical effectiveness for relieving RILI and related symptoms and signs and lead to improvement of Qol. However, more double-blind, multicenter, large-scale RCTs are needed to support this theory. Trial Registration. PROSPERO International prospective register of systematic reviews has registration number CRD42016043538.
\end{abstract}

\section{Introduction}

Thoracic radiation is an important curative and palliative treatment for lung cancer, esophagus cancer, breast cancer, mediastinal malignant tumors, and so on. Radiation induced lung injury (RILI) is one of the most common and severe side effects of thoracic radiotherapy [1]. RILI can occur in two phases, namely, early ( $<6$ months) when it is called radiation pneumonitis (RP) and late ( $>6$ months) when it is called radiation induced pulmonary fibrosis (RIPF) [1]. The reported rates of symptomatic RP after radiotherapy range from $9 \%$ to $51 \%$ [2-4]. Steroids and broad-spectrum antibiotics form the mainstay of treatment of RP. However their effectiveness is limited and their adverse effects are significant [1]. RP may trigger multiple repair mechanisms to restore lung function and remodel lung fibrosis; the incidence of RIPF varies from $8 \%$ to $43 \%[5,6]$. Unfortunately, there are no defined protocols or guidelines for the management of RIPF. Novel therapeutic approaches to improve the effectiveness of RILI treatment are required.

Chinese herbal medicine has been widely used alone or in combination with western conventional medicine to relieve RILI for more than 20 years. Multiple randomized clinical trials have suggested that Chinese herbal extractions (CHE) intervention can reduce symptoms and improve patient's quality of life and reduce proinflammatory cytokines and profibrosis cytokines [7-34]. In vivo, CHE can effectively relieve RP and RIPF, reducing proinflammatory cytokines (tumor necrosis factor- $\alpha$, TNF- $\alpha$ ) and profibrosis cytokines (transforming growth factor- $\beta$, TGF- $\beta$ ) in rat/mouse models of RILI [35-38]. However, there is no systematic review on effectiveness of CHE for relieving RILI. In this meta-analysis, the effectiveness and safety of CHE, for preventing and treating RILI, are evaluated for the first time. 
TABLE 1: RTOG and NCI-CTCAE Version 4.03 clinical grading scale of radiation pneumonitis.

\begin{tabular}{|c|c|c|}
\hline Grade & RTOG & NCI-CTCAE \\
\hline 1 & Mild dry cough not requiring medications & $\begin{array}{l}\text { Asymptomatic; clinical or diagnostic observations only; } \\
\text { intervention not indicated }\end{array}$ \\
\hline 2 & Cough requiring narcotic antitussives or dyspnoea not at rest & $\begin{array}{l}\text { Symptomatic; medical intervention indicated; limiting } \\
\text { instrumental ADL }\end{array}$ \\
\hline 3 & Severe cough not controlled by medications. Dyspnoea at rest & $\begin{array}{l}\text { Severe symptoms; limiting self-care ADL; oxygen } \\
\text { indicated }\end{array}$ \\
\hline 4 & Continuous oxygen or assisted ventilation & $\begin{array}{l}\text { Life-threatening respiratory compromise; urgent } \\
\text { intervention indicated (e.g., tracheotomy or intubation) }\end{array}$ \\
\hline 5 & Fatal & Death \\
\hline
\end{tabular}

\section{Methods}

2.1. Database and Search Strategies. Randomized Controlled Trials (RCTs) were identified by systematic searches in MEDLINE, Cochrane Controlled Trials, Springer, China National Knowledge Infrastructure (CNKI) database, and Wan-Fang database of China Science Periodical Database (CSPD) from the date of inception until April, 2016. The searching terms were "radiation induced lung injury/radiation pneumonitis/radiation induced pulmonary fibrosis" or "Traditional Chinese Medicine/herbal medicine" without language limitation. Reference lists from studies selected by electronic searching were hand searched.

2.2. Inclusion Criteria and Exclusion Criteria. We included trials with patients 18 years old and older, who have been clearly diagnosed with malignant tumors by pathology or cytology and were treated with thoracic radiotherapy. The dose of radiotherapy was not restricted. We ensured that patient age, gender, pathology, and disease stage were comparable among the treatment groups. CHE interventions should be approved by China Food and Drug Administration (CFDA), including single herb extractions and extractions from a compound of several herbs. The preparation method (e.g., oral decoction, powder, and injection) and delivery mode (e.g., oral, intravenous, and aerosol inhalation) of the $\mathrm{CHE}$ were not restricted. The control interventions were either placebo/no intervention, or conventional treatment such as Glucocorticoid and/or antibiotics. We also included studies that compared $\mathrm{CHE}$ combined with conventional medicine to conventional medicine alone. Studies with inadequate $\mathrm{CHE}$ quality control were excluded.

\subsection{Types of Outcome Measures}

(1) Incidence of RILI. Primary outcome was the incidence of RILI, including acute RP and RIPF. We considered the Radiation Therapy Oncology Group (RTOG) scale [39] or National Cancer Institute Common Terminology Criteria for Adverse Events (NCI-CTCAE) Version 4.03 scale [40] for the clinical grading of RILI (Table 1).

(2) Clinical Effectiveness. Total effective rate and remission rate of RILI patients were assessed according to Union for International Cancer Control (UICC) criteria [41].
Complete Remission (CR). The patients felt completely free from all symptoms, with normal results in X-ray or Computed Tomography (CT) examination for more than 4 weeks.

Partial Remission (PR). Symptoms alleviated obviously, with shadows reduced $\geq 50 \%$ in X-ray or CT examination for more than 4 weeks.

Not Cured (NC). Compared with before treatment, symptoms did not alleviate with shadows or fibrosis in X-ray or CT examination.

$$
\text { Total Effective Rate }=\mathrm{CR}+\mathrm{PR} .
$$

(3) Quality of Life (Qol). Patient's Qol was measured before and after radiotherapy using the Karnofsky performance status (KPS) scale. An increase of 10 points or more on the KPS score was considered improvement.

(4) Clinical Symptoms and Signs. Duration of fever, cough, asthma exacerbation, and colored sputum was evaluated.

(5) Inflammatory Cytokines. Interleukin-6 (IL-6), TGF- $\beta$, and TNF- $\alpha$ cytokines in plasma were evaluated.

(6) Thymus Dependent Lymphocytes (T Lymphocytes) Subgroups and Natural Killer (NK) Cells. T lymphocytes subgroups in peripheral blood were evaluated, including CD3+ lymphocytes, CD4+ lymphocytes, and CD8+ lymphocytes. Natural killer (NK) cells were also evaluated.

(7) Incidence of Adverse Events. Adverse events related to $\mathrm{CHE}$ intervention were extracted.

2.4. Data Extraction and Quality Assessment. The included studies were evaluated and the relevant data were extracted by two authors (BD and CD) independently. Differences were resolved by a third party. An electronic database was established using EndNotX7 software. The improved Jadad scale was used to assess the quality of the trials, including randomization; blinding of participants, personnel, and outcome assessors; completeness of outcome data; and other threats to validity [42]. High quality is $4-7$ points. Low quality is $1-3$ points.

2.5. Data Synthesis. Meta-analysis was conducted using RevMan 5.0 (Cochrane Collaboration, UK). Dichotomous 


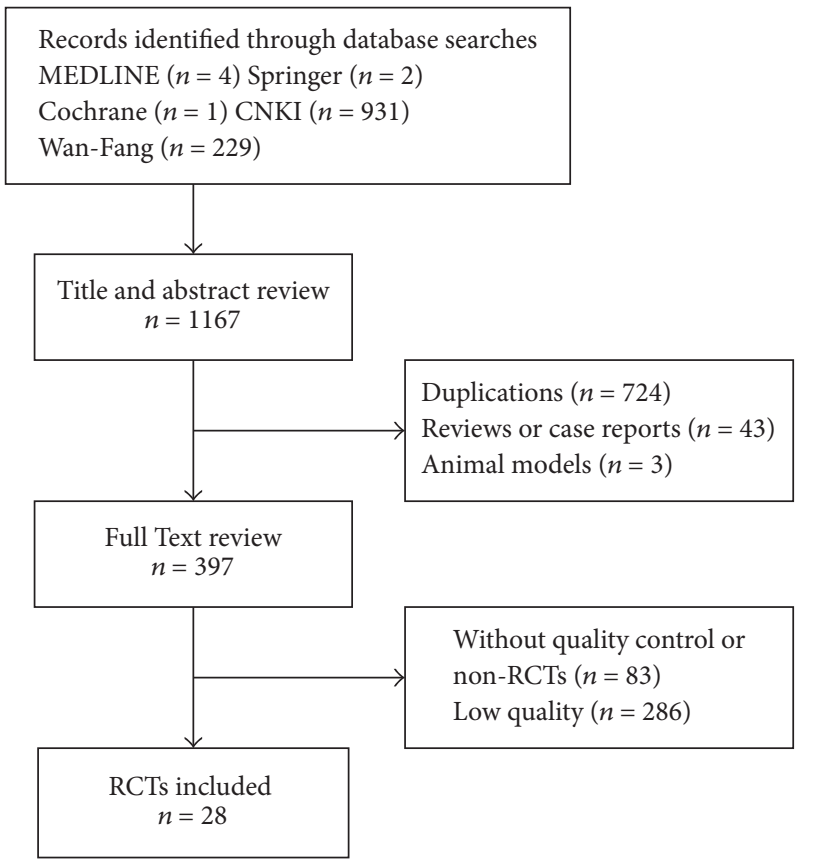

FIGURE 1: Flow chart of literature search.

data were expressed as odds ratio (OR) and continuous data were expressed as mean difference (MD). Heterogeneity between results was assessed by $I^{2}$ statistics and Cochran's Q-test, and $I^{2}>50 \%$ or $P<0.10$ was defined as indicating heterogeneity. The fixed-effect model was used in homogeneity data merging and the random-effects model was suitable for the merging of heterogeneous data [42]. Subgroups were divided according to constituents of $\mathrm{CHE}$ intervention. $\mathrm{CHE}$ containing the same ingredients was combined into 1 subgroup. Publication bias was evaluated by visual assessment of the asymmetry of funnel plots.

\section{Results}

3.1. Description of Studies and Methodological Quality (Figure 1 and Table 2). Primary searches identified 1167 references from the above databases. After duplicates, animal studies, case reports, reviews, and obvious ineligibility were removed, a total of 397 references were retrieved for text review. After assessment according to inclusion criteria and exclusion criteria, 28 studies were included [5-28]. Publication year of included studies ranging from 2006 to 2016, which in the years of 2012 and 2015 had a larger amount of studies than other years (14 studies, 55.82\% cases). All the studies were conducted in mainland China. Since all included studies were assessed to be of high quality (improved Jadad score of 4-7 points), the risk of bias in this systematic review was low. All studies employed computer software or random number table for randomization. Three studies used conventional medicine as control; only one study performed double-blinding. Eleven trials followed participants for 1 to 12 months.

3.2. Participants. In total, 2734 participants receiving thoracic radiotherapy were included. The average size of the study was 98 participants, ranging from 40 to 232 per study. All studies included adult patients, both male and female, and $63.68 \%$ participants were male patients. The entities of patients included lung cancer ( $n=1796$ cases), esophagus cancer ( $n=322$ cases), breast cancer $(n=164$ cases $)$, and mediastinal malignant tumors ( $n=33$ cases). The entities of the other 419 cases were not mentioned. Eighteen studies only enrolled inpatients ( $n=1577$ cases, 57.68\%), the remaining 10 studies did not report the setting ( $n=1157$ cases, $42.32 \%)$. The dose of radiotherapy varies from 30 to 76 Gy but mostly 38 to 70 Gy (15 studies). Thirteen studies used RTOG grade of RILI. Other studies used NCI-CTCAE, UICC, or other grading scales (described in references) to quantify the grade of RILI.

3.3. Intervention Comparisons (Table 3). Sixteen CHE were evaluated, including 14 injections and 2 oral medicines. Shen Mai Injection (SMI) and Tan Re Qing Injection (TRQI) were most widely used in these studies. Six studies evaluated extractions from single herb or active ingredient(s). The other 22 studies evaluated extractions from Traditional Chinese medicine (TCM) compound prescriptions. The most popular herbs were Radix Ginseng (Rubra)/Radix Codonopsis (9 times). Radix Scutellariae, Flos Lonicerae (5 times), Fructus Forsythiae (5 times), and Rhizoma Chuanxiong (5 times) were also popular.

Thirteen studies ( $n=1470$ cases) compared CHE to placebo or no treatment. Twelve studies ( $n=937$ cases) tested CHE combined with Glucocorticoid and/or antibiotics, compared to the same western medications for RILI management. And other 3 studies ( $n=327$ cases) tested $\mathrm{CHE}$ compared to Glucocorticoid and/or antibiotics. Three kinds of administration methods were employed in these 28 studies, 


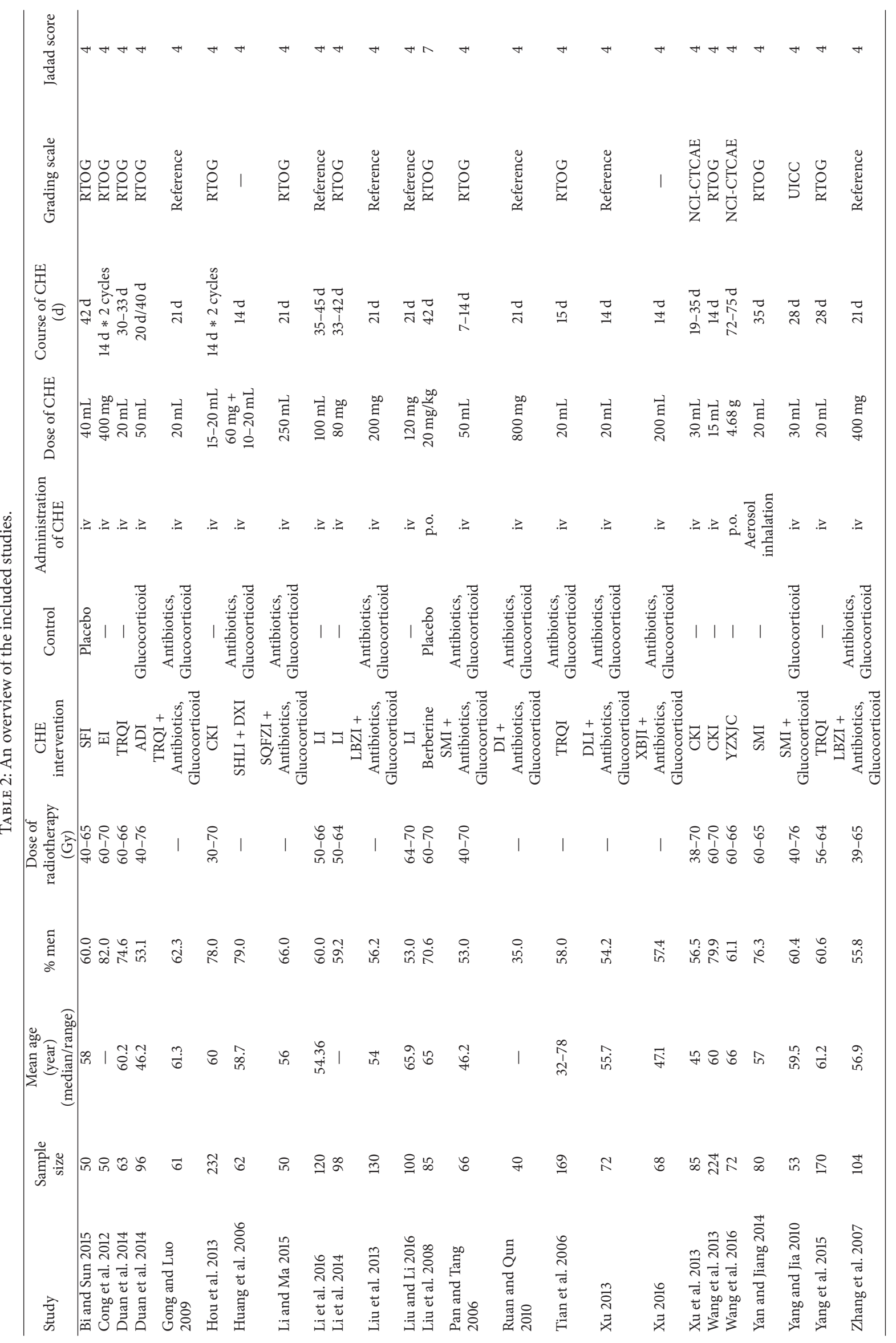




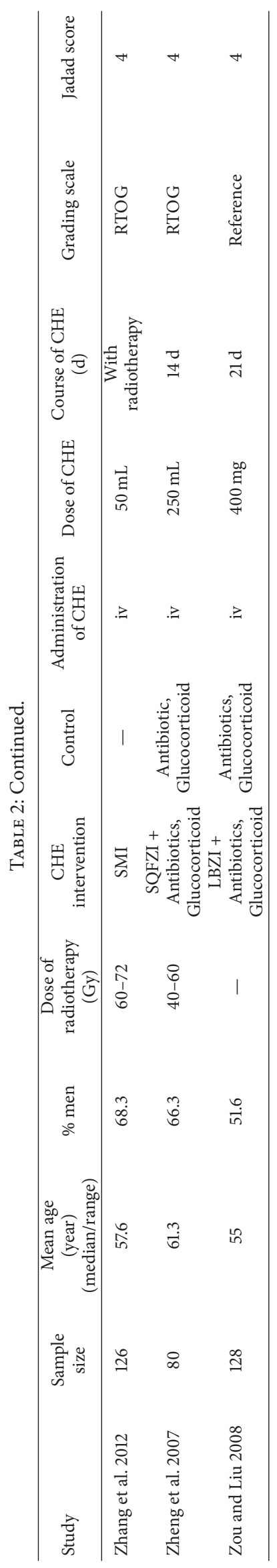


TABLE 3: Constituents of included Chinese herbal extractions.

\begin{tabular}{|c|c|c|}
\hline Chinese herbal extraction & Abbreviation & Medicinal herbs \\
\hline Ai Di Injection & ADI & $\begin{array}{l}\text { Radix Ginseng, Radix Astragali, Radix Et } \\
\text { Caulis Acanthopanacis Senticosi, Mylabris }\end{array}$ \\
\hline Berberine & Berberine & Rhizoma Coptidis \\
\hline Compound Kushen Injection & CKI & $\begin{array}{c}\text { Radix Sophorae Flavescentis, Rhizoma } \\
\text { Hterosmilacis }\end{array}$ \\
\hline Danshen Injection & $\mathrm{DI}$ & Radix Salviae Miltiorrhizae \\
\hline Danshen Ligustrazine Injection & DLI & $\begin{array}{c}\text { Radix Salviae Miltiorrhizae, Rhizoma } \\
\text { Chuanxiong }\end{array}$ \\
\hline Dan Xiang Injection & DXI & $\begin{array}{c}\text { Radix Salviae Miltiorrhizae, Lignum } \\
\text { Dalbergiae Odoriferae }\end{array}$ \\
\hline Elemene Injection & EI & Radix Curcumae/Rhizoma Curcumae \\
\hline Lian Bi Zhi Injection & LBZI & Herba Andrographis \\
\hline Ligustrazine Injection & LI & Rhizoma Chuanxiong \\
\hline Shen Fu Injection & SFI & $\begin{array}{c}\text { Radix Ginseng Rubra, Radix Aconiti } \\
\text { Lateralis Preparata }\end{array}$ \\
\hline Shuang Huang Lian Injection & SHLI & $\begin{array}{c}\text { Fructus Forsythiae, Flos Lonicerae, Radix } \\
\text { Scutellariae }\end{array}$ \\
\hline Shen Mai Injection & SMI & Radix Ginseng, Radix Ophiopogonis \\
\hline Shen Qi Fu Zheng Injection & SQFZI & Radix Codonopsis, Radix Astragali \\
\hline Tan Re Qing Injection & TRQI & $\begin{array}{l}\text { Radix Scutellariae, Fel ursi, Cornu gorais, } \\
\text { Flos Lonicerae, Fructus Forsythiae }\end{array}$ \\
\hline Xue Bi Jing Injection & $\mathrm{XBJI}$ & $\begin{array}{c}\text { Flos Carthami, Radix Paeoniae Rubra, } \\
\text { Rhizoma Chuanxiong, Radix Salviae } \\
\text { Miltiorrhizae, Radix Angelicae Sinensis }\end{array}$ \\
\hline Yang Zheng Xiao Ji Capsule & YZXJC & $\begin{array}{c}\text { Radix Astragali, Fructus Ligustri Lucidi, } \\
\text { Radix Ginseng, Rhizoma Curcumae, } \\
\text { Ganoderma, and so on }\end{array}$ \\
\hline
\end{tabular}

including intravenous drip (25 studies), oral administration (2 studies), and aerosol inhalation (1 study). The duration of intervention varied from 7 days to 75 days but mostly 14 to 35 days (22 studies).

\subsection{Preventing Effects of Interventions}

3.4.1. Incidence of Acute Radiation Pneumonitis (Figure 2). Sixteen studies reported incidence of grades 1-5 acute RP. Ten CHE were evaluated and 1789 cases were included. The incidence of acute RP in CHE group was 34.76\% and control group was $56.07 \%$. Meta-analysis showed incidence of acute $\mathrm{RP}$ was significantly reduced in $\mathrm{CHE}$ group $(P<0.01$, OR $=0.34,95 \%$ CI $[0.28-0.43])$. Subgroup analysis showed all $\mathrm{CHE}$ reduced the incidence of acute RP, except for Elemene Injection (EI).

3.4.2. Incidence of Radiation Induced Pulmonary Fibrosis (Figure 3). Five trials ( $n=573$ cases) reported incidence of RIPF, and three CHE were evaluated. The incidence of RIPF in $\mathrm{CHE}$ group was $22.38 \%$, with $44.60 \%$ in control group. Subgroup analysis showed that all CHE reduced the incidence of radiation pulmonary fibrosis $(P<0.01, \mathrm{OR}=0.35,95 \% \mathrm{CI}$ [0.24-0.50]).

\subsection{Therapeutic Effects of Interventions}

3.5.1. Total Effective Rate (Figure 4). Twelve trials included 1069 cases that already developed RILI and reported curative effects of $9 \mathrm{CHE}$ injections intervention. The total effective rate (TER) of CHE group was $90.91 \%$, and control group was $71.29 \%$. Meta-analysis showed TER of RILI patients increased significantly in CHM group $(P<0.01, \mathrm{OR}=4.44,95 \% \mathrm{CI}$ [3.10-6.36]). Subgroup analysis showed all CHE injections significantly increased the TER of RILI patients $(P<0.01$ or $P<0.05$ ), except for Danshen Ligustrazine Injection (DLI), Shen Qi Fu Zheng Injection (SQFZI), and Xue Bi Jing Injection (XBJI).

3.5.2. Complete Remission Rate (Figure 5). Eleven trials (1028 cases) evaluated the complete remission (CR) rate of $8 \mathrm{CHE}$ injections intervention. The $\mathrm{CR}$ of $\mathrm{CHE}$ group was $52.26 \%$ and control group was $33.13 \%$. Meta-analysis showed CR of RILI patients increased significantly in CHE group $(P<$ $0.01, \mathrm{OR}=2.43,95 \% \mathrm{CI}[1.86-3.17])$. Subgroup analysis showed DLI, Lian Bi Zhi Injection (LBZI), TRQI, and XBJI significantly increased the CR $(P<0.01$ or $P<0.05)$.

3.6. Percentage of Quality of Life Improvement (Figure 6). Eight studies reported percentage of Qol improvement. Seven 


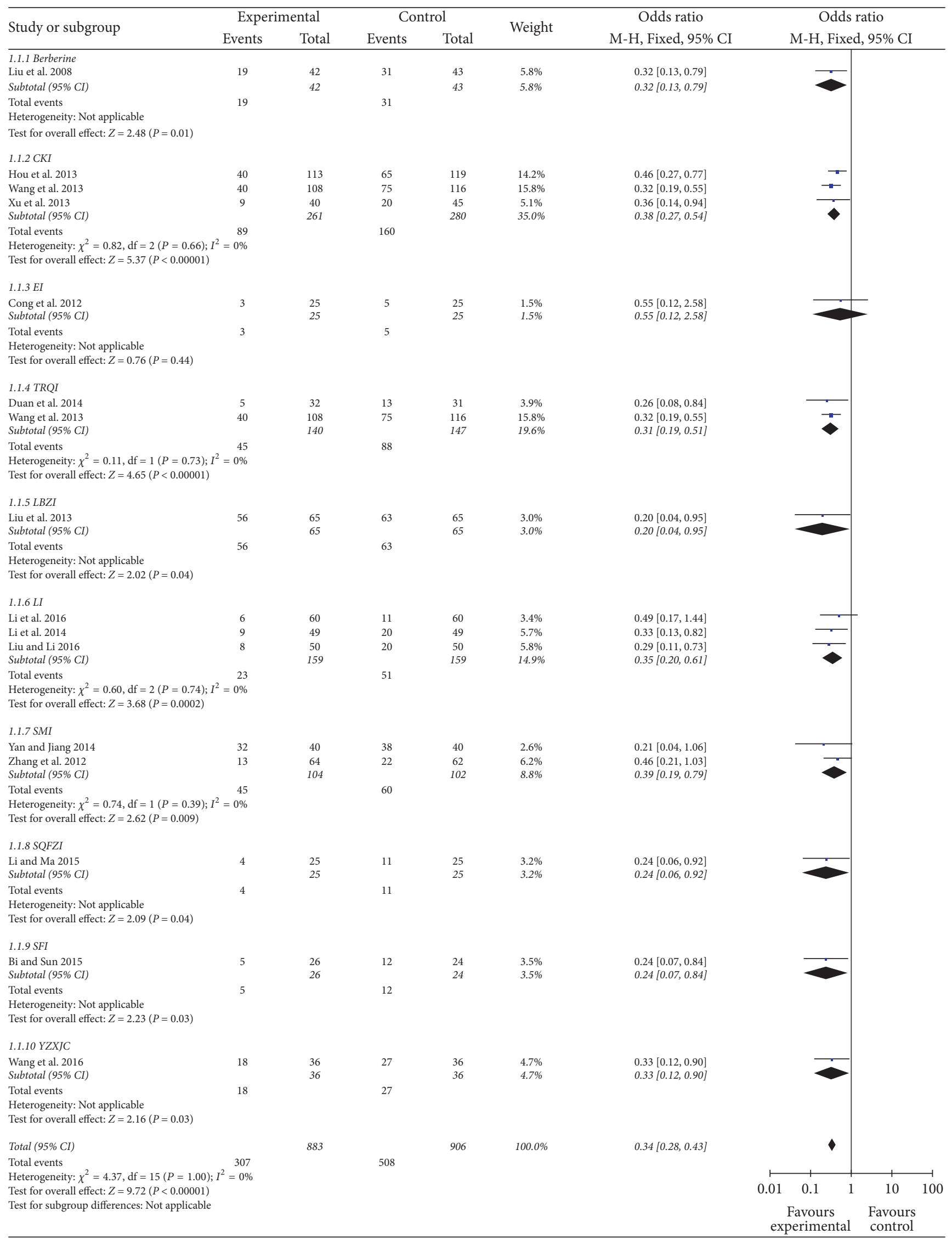

FIGURE 2: Forest plot of comparison: incidence of acute radiation pneumonitis. 


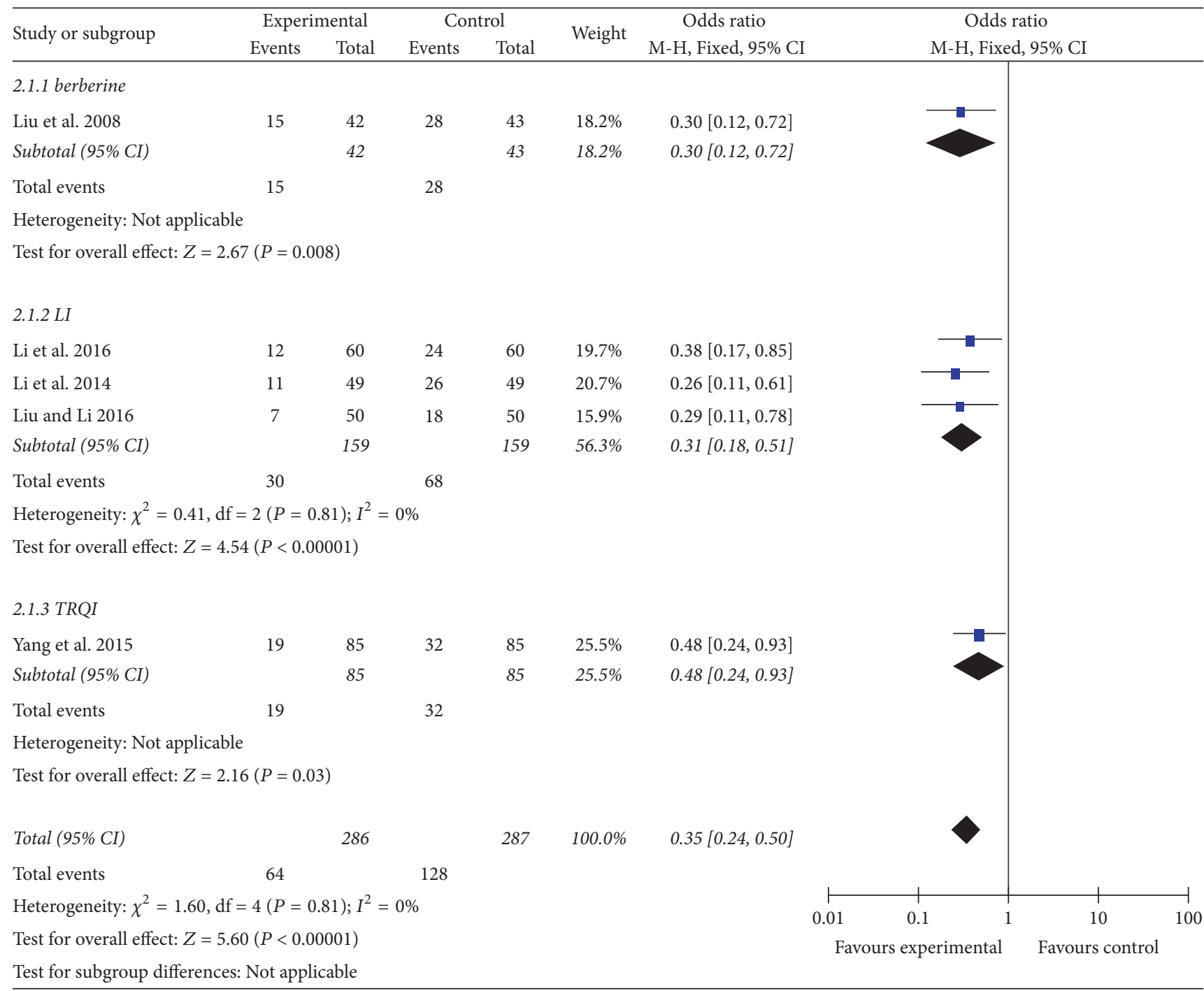

FIGURE 3: Forest plot of comparison: incidence of radiation induced pulmonary fibrosis.

CHE injections were evaluated and 719 cases were included. The percentage of Qol improvement in $\mathrm{CHE}$ group was $60.67 \%$, with $33.33 \%$ in control group. Meta-analysis showed the percentage of Qol improvement increased significantly in CHE group $(P<0.01, \mathrm{OR}=3.61,95 \% \mathrm{CI}[2.58-5.06])$. Subgroup analysis showed all CHE injections significantly increased percentage of Qol improvement $(P<0.01$ or $P<$ 0.05), except for EI, LBZI, and TRQI.

3.7. Clinical Symptoms and Signs (Supplemental Figure 1). Two studies ( $n=199$ cases) investigated the duration of fever, cough, asthma, and colored sputum. Meta-analysis and subgroup analysis showed LBZI and TRQI significantly reduced the duration of fever individually $(P<0.01, \mathrm{MD}=-1.23$, 95\% CI [-1.81--0.66]). The duration of asthma and colored sputum also reduced significantly $(P<0.01 \mathrm{MD}=-1.43$, 95\% CI $[-2.50--0.36] ; P<0.05, \mathrm{MD}=-1.99,95 \% \mathrm{CI}$ [-3.71--0.26]) (see Supplementary Material available online at https://doi.org/10.1155/2017/2141645).

\subsection{Inflammatory and Fibrosis Cytokines (Supplemental Figure 2)}

3.8.1. TGF- $\beta$ Cytokine. Four studies ( $n=368$ cases) investigated TGF- $\beta$ cytokine in plasma after treatments of $3 \mathrm{CHE}$ individually. Meta-analysis and subgroup analysis showed these CHE significantly reduced TGF- $\beta$ cytokine in plasma individually $(P<0.01, \mathrm{MD}=-3.46,95 \% \mathrm{CI}[-4.20--2.73])$.

3.8.2. TNF- $\alpha$ Cytokine. Two studies ( $n=140$ cases) investigated TNF- $\alpha$ cytokine in plasma after Danshen Injcection (DI) or Ligustrazine Injection (LI) treatment. Meta-analysis and subgroup analysis showed these injections reduced TNF$\alpha$ cytokine in plasma individually $(P<0.01, \mathrm{MD}=-1.42,95 \%$ CI $[-1.60--1.25])$.

3.8.3. IL-6 Cytokine. Three studies ( $n=158$ cases) investigated IL- 6 cytokine in plasma after treatments of $3 \mathrm{CHE}$ injections individually. Meta-analysis and subgroup analysis 


\begin{tabular}{|c|c|c|c|c|c|c|c|c|}
\hline \multirow{3}{*}{$\begin{array}{l}\text { Study or subgroup } \\
3.1 .1 A D I\end{array}$} & \multicolumn{2}{|c|}{ Experimental } & \multicolumn{2}{|c|}{ Control } & \multirow{2}{*}{ Weight } & \multirow{2}{*}{$\begin{array}{c}\text { Odds ratio } \\
\text { M-H, Fixed, 95\% CI }\end{array}$} & \multirow{2}{*}{\multicolumn{2}{|c|}{$\begin{array}{c}\text { Odds ratio } \\
\text { M-H, Fixed, 95\% CI }\end{array}$}} \\
\hline & \multirow[t]{2}{*}{ Events } & \multirow[t]{2}{*}{ Total } & \multirow[t]{2}{*}{ Events } & \multirow[t]{2}{*}{ Total } & & & & \\
\hline & & & & & & & & \\
\hline Duan et al. 2014 & 44 & 50 & 30 & 46 & $12.2 \%$ & $3.91[1.37,11.14]$ & & \\
\hline Subtotal (95\% CI) & & 50 & & 46 & $12.2 \%$ & $3.91[1.37,11.14]$ & & \\
\hline Total events & 44 & & 30 & & & & & \\
\hline Heterogeneity: Not a & & & & & & & & \\
\hline Test for overall effect & & & & & & & & \\
\hline $3.1 .2 \mathrm{DI}$ & & & & & & & & \\
\hline Ruan and Qun 2010 & 18 & 20 & 11 & 20 & $3.6 \%$ & $7.36[1.34,40.55]$ & & 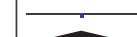 \\
\hline Subtotal (95\% CI) & & 20 & & 20 & $3.6 \%$ & $7.36[1.34,40.55]$ & & \\
\hline Total events & 18 & & 11 & & & & & \\
\hline Heterogeneity: Not a & & & & & & & & \\
\hline Test for overall effect & & & & & & & & \\
\hline $3.1 .3 \mathrm{DLI}$ & & & & & & & & \\
\hline Xu 2013 & 34 & 36 & 28 & 36 & $5.1 \%$ & $4.86[0.95,24.75]$ & & \\
\hline Subtotal (95\% CI) & & 36 & & 36 & $5.1 \%$ & $4.86[0.95,24.75]$ & & \\
\hline Total events & 34 & & 28 & & & & & \\
\hline Heterogeneity: Not a & & & & & & & & \\
\hline Test for overall effect & & & & & & & & \\
\hline 3.1.4 LBZI & & & & & & & & \\
\hline Liu et al. 2013 & 63 & 65 & 56 & 65 & $5.6 \%$ & $5.06[1.05,24.43]$ & & \\
\hline Zhang et al. 2007 & 51 & 53 & 46 & 52 & $5.7 \%$ & $3.33[0.64,17.30]$ & & \\
\hline Zou and Liu 2008 & 61 & 64 & 56 & 64 & $8.6 \%$ & $2.90[0.73,11.50]$ & & \\
\hline Subtotal (95\% CI) & & 182 & & 181 & $19.9 \%$ & $3.64[1.52,8.70]$ & & \\
\hline Total events & 175 & & 158 & & & & & \\
\hline Heterogeneity: $\chi^{2}=$ & $87) ; I^{2}=$ & & & & & & & \\
\hline Test for overall effect & & & & & & & & \\
\hline 3.1.5 SHLI + DXI & & & & & & & & \\
\hline Huang et al. 2006 & 30 & 32 & 21 & 30 & $4.4 \%$ & $6.43[1.26,32.83]$ & & \\
\hline Subtotal (95\% CI) & & 32 & & 30 & $4.4 \%$ & $6.43[1.26,32.83]$ & & \\
\hline Total events & 30 & & 21 & & & & & \\
\hline Heterogeneity: Not a & & & & & & & & \\
\hline Test for overall effect & & & & & & & & \\
\hline 3.1.6 SMI & & & & & & & & \\
\hline Pan and Tang 2006 & 28 & 32 & 22 & 34 & $8.7 \%$ & $3.82[1.08,13.49]$ & & \\
\hline Yang and Jia 2010 & 23 & 27 & 14 & 26 & $6.9 \%$ & $4.93[1.33,18.31]$ & & \\
\hline Subtotal (95\% CI) & & 59 & & 60 & $15.6 \%$ & $4.31[1.74,10.70]$ & & \\
\hline Total events & 51 & & 36 & & & & & \\
\hline Heterogeneity: $\chi^{2}=$ & $78) ; I^{2}=$ & & & & & & & \\
\hline Test for overall effect & & & & & & & & \\
\hline 3.1.7 SQFZI & & & & & & & & \\
\hline Zheng et al. 2007 & 44 & 48 & 24 & 32 & $7.8 \%$ & $3.67[1.00,13.44]$ & & \\
\hline Subtotal (95\% CI) & & 48 & & 32 & $7.8 \%$ & $3.67[1.00,13.44]$ & & \\
\hline Total events & 44 & & 24 & & & & & \\
\hline Heterogeneity: Not a & & & & & & & & \\
\hline Test for overall effect & & & & & & & & \\
\hline 3.1.8 TRQI & & & & & & & & \\
\hline Tian et al. 2006 & 74 & 89 & 39 & 80 & $22.6 \%$ & $5.19[2.56,10.52]$ & & \\
\hline Subtotal $(95 \%$ CI) & & 89 & & 80 & $22.6 \%$ & $5.19[2.56,10.52]$ & & \\
\hline Total events & 74 & & 39 & & & & & \\
\hline Heterogeneity: Not a & & & & & & & & \\
\hline Test for overall effect & $001)$ & & & & & & & \\
\hline 3.1.9 XBJI & & & & & & & & \\
\hline Xu 2016 & 30 & 34 & 23 & 34 & $8.8 \%$ & $3.59[1.01,12.73]$ & & \\
\hline Subtotal (95\% CI) & & 34 & & 34 & $8.8 \%$ & $3.59[1.01,12.73]$ & & \\
\hline Total events & 30 & & 23 & & & & & \\
\hline Heterogeneity: Not a & & & & & & & & \\
\hline Test for overall effect & & & & & & & & \\
\hline Total (95\% CI) & & 550 & & 519 & $100.0 \%$ & $4.44[3.10,6.36]$ & & \\
\hline Total events & 500 & & 370 & & & & & \\
\hline Heterogeneity: $\chi^{2}=$ & $1.00) ; I^{2}$ & & & & & & 0.01 & 10 \\
\hline Test for overall effect & $001)$ & & & & & & $.01 \quad 0.1$ & 10 \\
\hline Test for subgroup dif & cable & & & & & & $\begin{array}{c}\text { Favours } \\
\text { experimental }\end{array}$ & $\begin{array}{l}\text { Favours } \\
\text { control }\end{array}$ \\
\hline
\end{tabular}

FIGURE 4: Forest plot of comparison: total effective rate of radiation induced lung injury. 


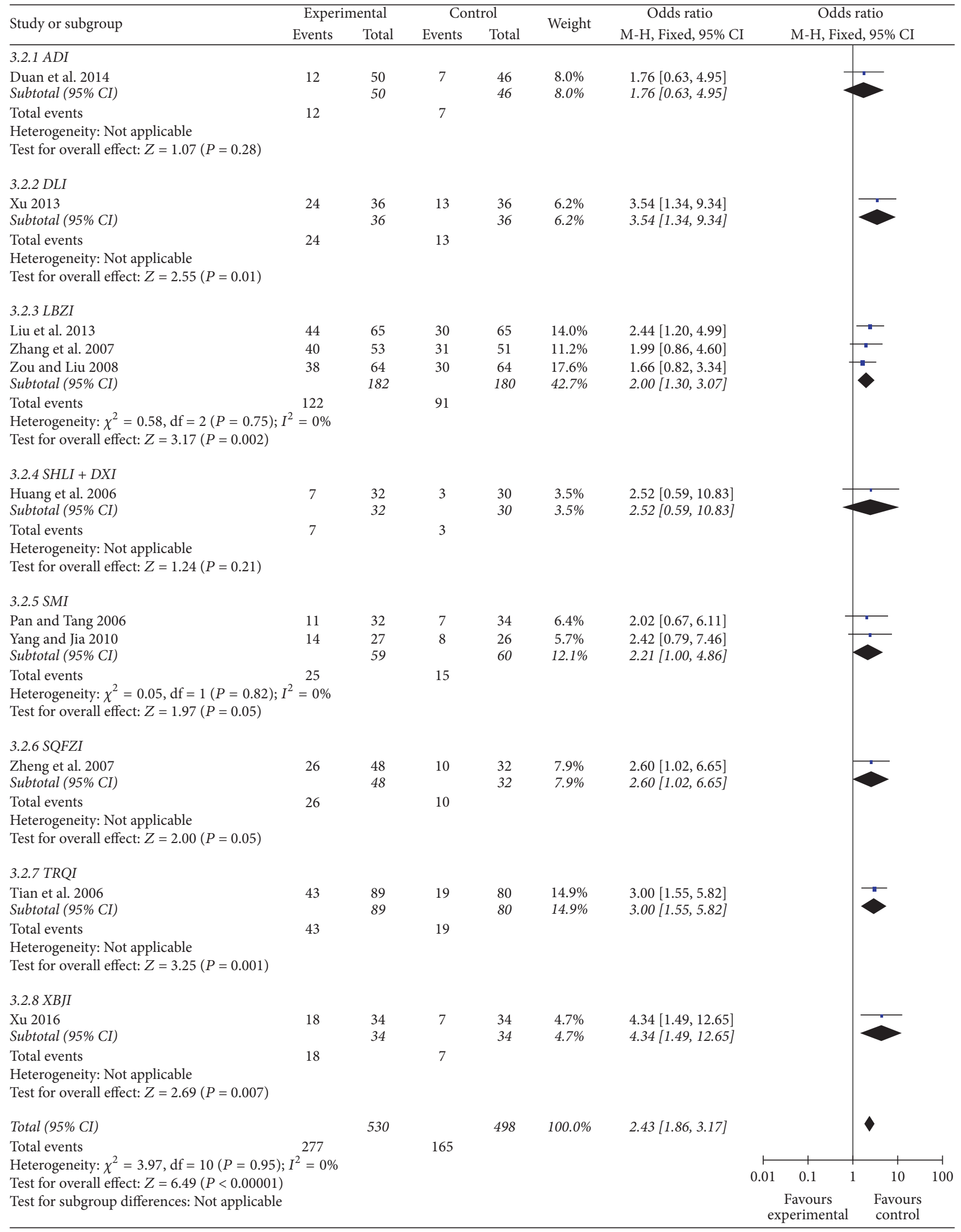




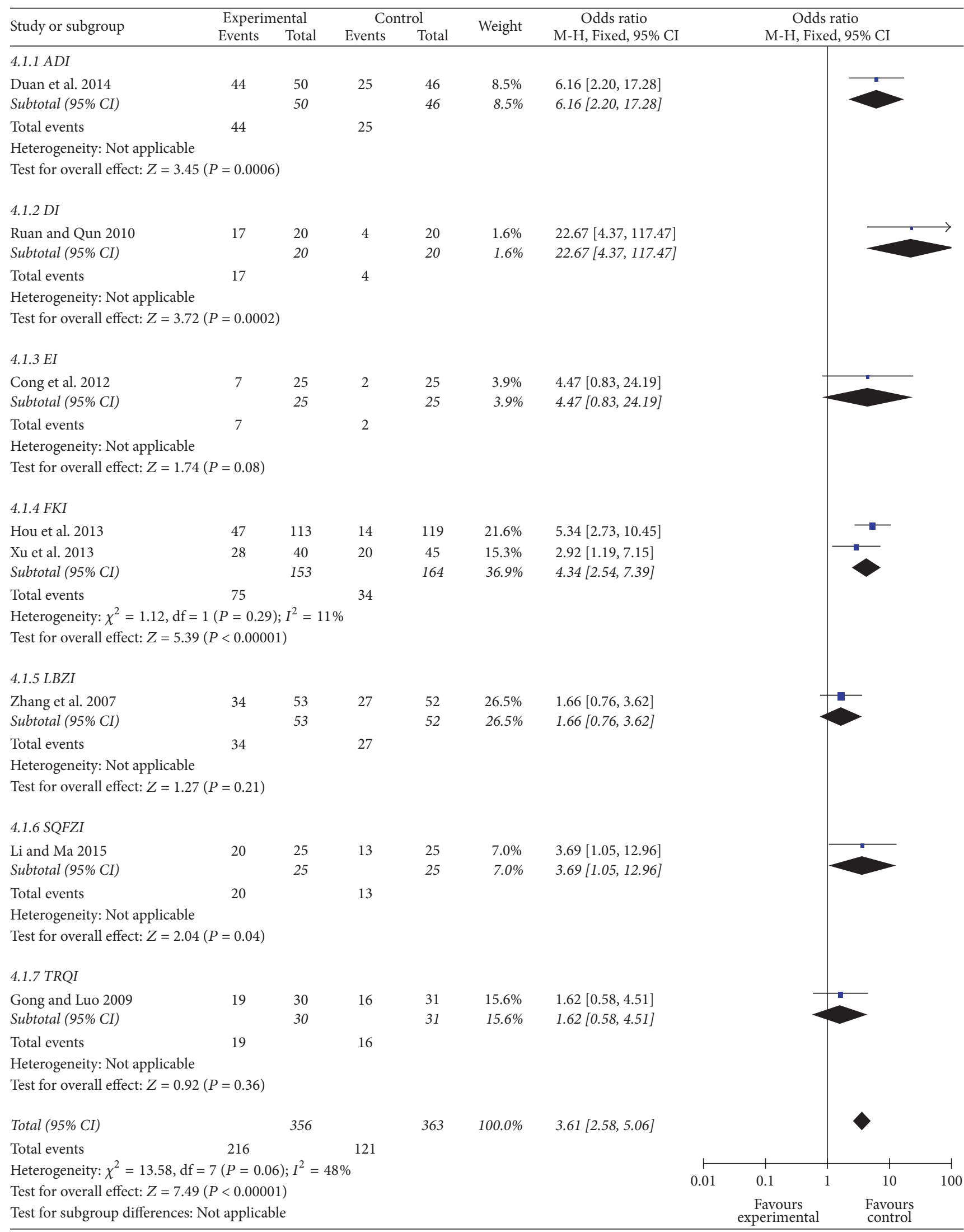

FIGURE 6: Forest plot of comparison: percentage of quality of life improvement. 
showed these injections significantly reduced plasma IL-6 cytokine individually $(P<0.01, \mathrm{MD}=-25.17,95 \% \mathrm{CI}$ $[-42.68--7.66])$.

3.9. Thymus Dependent Lymphocytes Subgroups and Natural Killer Cells (Supplemental Figure 3). Two studies $(n=211$ cases) investigated subset of $\mathrm{T}$ lymphocytes in peripheral blood after Compound Kushen Injection (CKI) or SMI treatment. Meta-analysis and subgroup analysis showed these injections significantly increased the levels of CD3+ T lymphocytes $(P<0.01, \mathrm{MD}=9.63,95 \% \mathrm{CI}[3.68-15.58])$, CD4+ T lymphocytes $(P<0.01, \mathrm{MD}=10.16,95 \% \mathrm{CI}[6.58-13.74])$, and NK cells $(P<0.05, \mathrm{MD}=6.25,95 \% \mathrm{CI}$ [5.81-6.70] $)$, while changes of CD8+ T lymphocytes were not statistical differences.

3.10. Adverse Events and Publication Bias (Figure 7). No adverse events associated with CME interventions were reported among included studies. Exploration of the funnel plot for incidence of acute RP, TER, and CR of RILI patients between CME group and control suggested almost symmetry; no significant publication bias was showed.

\section{Discussions}

Radiation is one of the main therapies for lung cancer and other malignancies, but RILI is a dose-limiting factor for radiotherapy and is sometimes life-threatening. RILI limits the effectiveness, dose, and schedule of radiotherapy and reduces the Qol of patients. At present, there is a trend emphasizing the Qol in cancer patients receiving radiotherapy in addition to its cancer-killing effects. Thus, the prevention of RILI with CHE represents a new avenue for dealing with these side effects of radiotherapy.

Early RILI manifests as acute RP, occurs between 1 and 3 months of radiation, and is characterized by the loss of type I pneumocytes, increases in capillary permeability, interstitial edema, and alveolar capillary congestion, and the accumulation of inflammatory and immune cells from peripheral blood in the alveolar space. In this stage, LBZI, SMI, and TRQI reduced the incidence of acute RP and increased TER and CR in RP patients. CKI, LI, Shen Fu Injection (SFI), and SQFZI, prevented the incidence of RP, while Ai Di Injection (ADI), DI, DLI, Shuang Huang Lian Injection (SHLI), and XBJI increased TER or CR in acute RP patients. The proinflammatory cytokines (TNF- $\alpha$ and IL-6) were reduced by DI and SFI. CKI and SMI improved T lymphocytes subgroups in peripheral blood.

Radiation induces a second wave release of profibrosis cytokines (including TGF- $\beta$ ), around 6-8 weeks after radiation. The increased TGF- $\beta$ causes influx of fibroblasts and their conversion to myofibroblasts, thus causing lung fibrosis. This in turn causes hypoxia which induces profibrosis and proangiogenic cytokines release. The vicious cycle continues and leads to chronic lung disease [1]. In this stage, berberine, LI, and TRQI significantly reduced the incidence of RIPF. TGF- $\beta$ decreased significantly after berberine, EI, and TRQI intervention; therefore the vicious cycle was broken.
RILI is not recorded in classic TCM books. Based on syndrome differentiation and treatment, TCM oncologists believe radiation falls under the category of heat toxin in TCM theory. CKI, TRQI, SHLI, and LBZI are extracted from herbs with clearing heat and removing toxicity efficacy. These treatments reduced the duration of fever and colored sputum and relieved pneumonia in vivo [35]. CKI have anticancer effects for various types of solid tumors, such as non-small-cell lung cancer, liver cancer, breast cancer, and so on $[43,44]$. Matrine (the main chemical ingredient of CKI) and its derivatives exhibit a variety of pharmacological activities including anticancer, anti-inflammatory, and antifibrotic effects $[43,44]$. They could also prevent or reduce chemotherapy- and/or radiotherapy-induced toxicity and reduce cancer induced pain $[45,46]$. Radix Scutellariae, Flos Lonicerae, and Fructus Forsythiae in TRQI and SHLI have anti-inflammatory and antioxidative properties in various models of lung injury [47-49]. Baicalin, extracted and purified from Radix Scutellariae, exerts an inhibitory effect on airway inflammation, and this effect may be associated with the inhibition of CC chemokine receptor 7 (CCR7) and its ligands CCL19/CCL21 [47]. Luteolin, an active flavonoid compound isolated from Flos Lonicerae, has a potent antifibrotic activity; this effect was mediated, at least in part, by inhibition of lung inflammation and suppression of myofibroblast differentiation as well as epithelial-to-mesenchymal transition [48]. Forsythin, an active ingredient extracted from Fructus Forsythiae, exerts anti-inflammatory action via suppressing LPS-induced activation of JAK-STATs and p38 MAPKs signaling and production of ROS in macrophage cells [49]. Andrographolide, from Herba Andrographis in LBZI, markedly hampered the activation of nuclear factor- $\kappa \mathrm{B}(\mathrm{NF}-$ $\kappa \mathrm{B})$ and NLRP3 inflammasome both in vivo and in vitro thus decreasing levels of TNF- $\alpha$ and IL-1 $\beta$ [50].

In TCM theory, heat toxin burns lung Yin, injures Fluid, and consumes Qi. ADI, SFI, SMI, SQFZI, and Yang Zheng Xiao Ji Capsule (YZXJC) are extracted from herbs with reinforcing Qi and nourishing Yin efficacy [36, 37]. Radix Ginseng is a main component of these $5 \mathrm{CHE}$. A high pretreatment dose of ginseng extractions resulted in a marked attenuation of the severity of inflammatory changes in lung tissue in a mouse model of RILI and led to significant reductions in TNF- $\alpha$ and TGF- $\beta 1$ cytokines [51]. In vivo, ginseng extractions and SFI led to significant reductions in TNF- $\alpha$ and TGF- $\beta 1$ cytokines. This may be a key mechanism behind the preventive effects of these 4 injections on RILI [36]. Ginsenoside $\operatorname{Rg} 3$ a main ingredient of ginseng extractions was able to sensitize A549 and H1299 lung carcinoma cells to $\gamma$-radiation and significantly enhance the efficacy of radiation therapy in C57BL/6 mice bearing a Lewis lung carcinoma cell xenograft tumor [52]. Radix Astragali in SQFZI and YZXJC is considered as potential and powerful exogenous source of antioxidants. It provides significant protection against lung injury in various models of oxidative stress-related disease [53].

Lung fibrosis falls under the category of blood stasis in TCM theory. Radix Salviae Miltiorrhizae, Rhizoma Chuanxiong, Radix Curcumae, and Rhizoma Curcumae promote blood circulation to remove blood stasis. Their extractions 

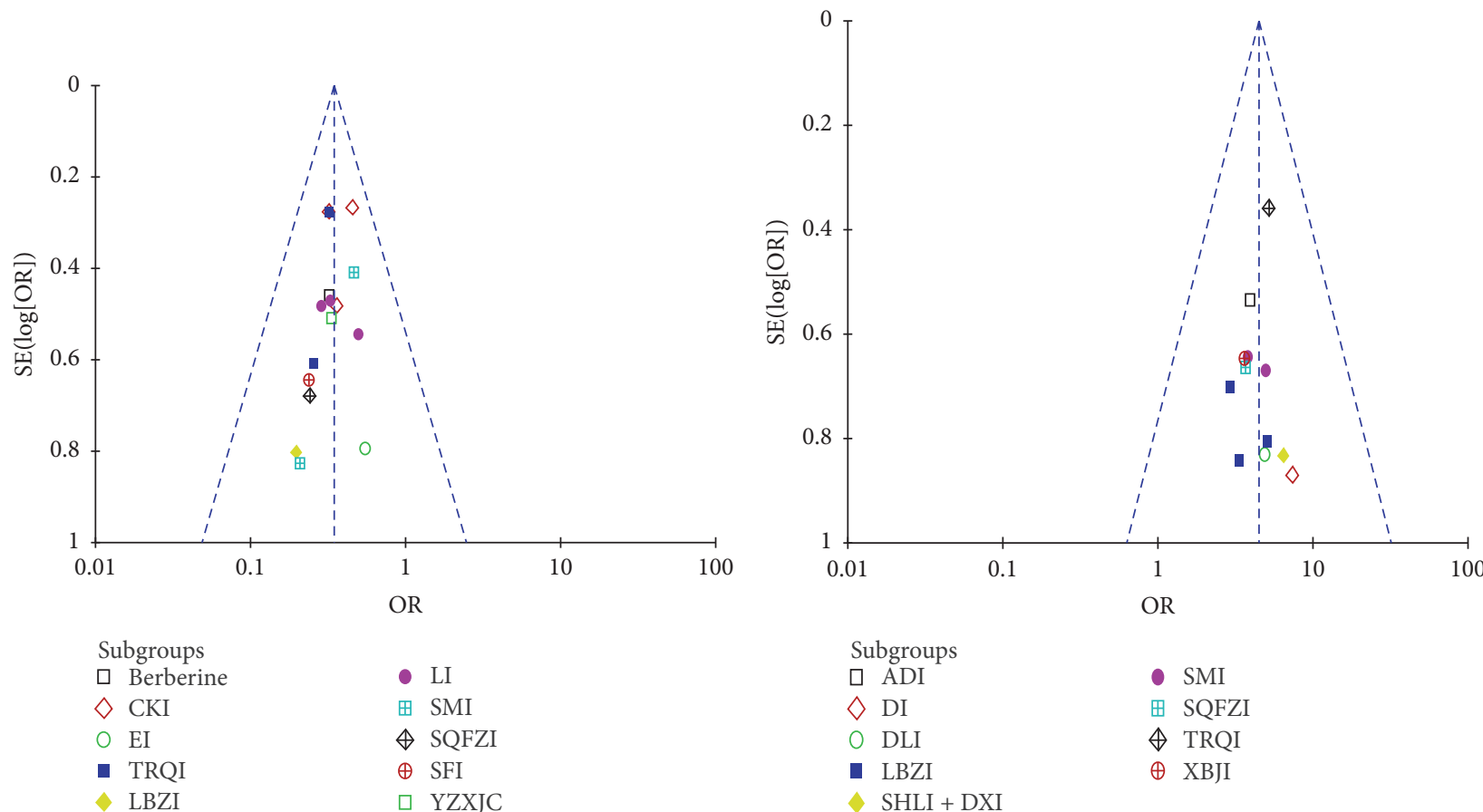

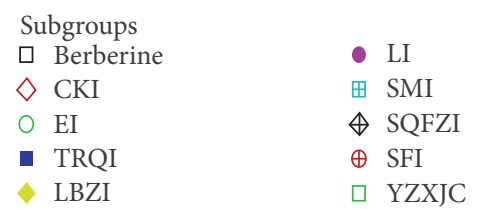

(a) (b)

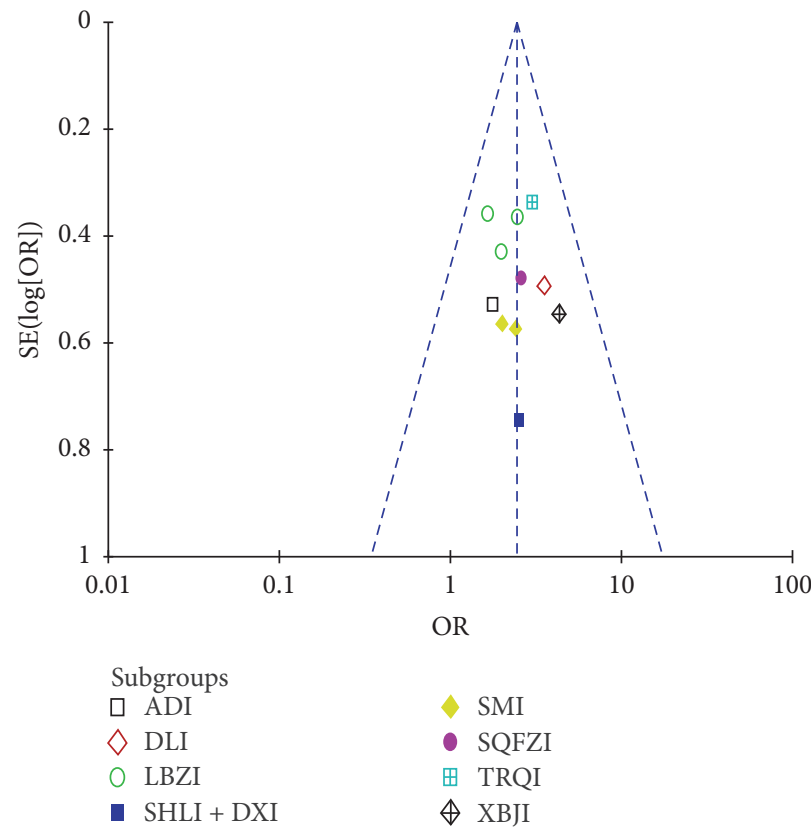

(c)

FIGURE 7: Funnel plot analysis of risk of bias. (a) Incidence of acute radiation pneumonitis. (b) Total effective rate of radiation induced lung injury. (c) Complete remission rate of radiation induced lung injury.

tanshinone, LI, and EI relieved RILI in vivo [38] and have antitumor effects against lung cancer [54-56]. EI also enhances the radiosensitivity of lung adenocarcinoma [57].

This review has its limitations. We only included studies published in journals. Dissertations and conference papers were not included. Only high quality (improved Jadad score $\geq 4$ points) trials were included. We excluded 285 trials with low quality or insufficient information for assessing risk of bias. We only included studies about herbal extractions approved by CFDA, herbal extractions without quality control were excluded. Therefore, it may not be possible to achieve a complete summary of all existent evidence. Studies conducted in different countries, which would strengthen the results on the different scales, were lacking. Future trials 
should assure adequate concealment of allocation and blinding of outcome assessors. And long-term outcomes, such as PFS (Progression-Free-Survival) and OS (Overall survival), should also be evaluated.

\section{Conclusions}

From our study, we found that herbal medicine extractions intervention may have clinical effectiveness for relieving RILI and related symptoms and signs and lead to improvement of Qol. However, the evidence is not sufficient. More doubleblind, multicenter, large-scale RCTs are needed to draw definitive conclusions.

\section{Conflicts of Interest}

The authors declare that there are no conflicts of interest regarding the publication of this paper.

\section{Authors' Contributions}

Bo Deng and Chao Deng contributed equally to this paper.

\section{Acknowledgments}

This work was supported by National Fund of Natural Sciences no. 81473524 of China.

\section{References}

[1] P. Giridhar, S. Mallick, G. K. Rath, and P. K. Julka, "Radiation induced lung injury: prediction, assessment and management," Asian Pacific Journal of Cancer Prevention, vol. 16, no. 7, pp. 2613-2617, 2015.

[2] H. Yamashita, W. Takahashi, A. Haga, and K. Nakagawa, "Radiation pneumonitis after stereotactic radiation therapy for lung cancer," World Journal of Radiology, vol. 6, no. 9, pp. 708715, 2014.

[3] M. C. Stauder, O. K. MacDonald, K. R. Olivier et al., "Early pulmonary toxicity following lung stereotactic body radiation therapy delivered in consecutive daily fractions," Radiotherapy and Oncology, vol. 99, no. 2, pp. 166-171, 2011.

[4] M. Kim, J. Lee, B. Ha, R. Lee, K. Lee, and H. S. Suh, "Factors predicting radiation pneumonitis in locally advanced nonsmall cell lung cancer," Radiation Oncology Journal, vol. 29, no. 3, pp. 181-190, 2011.

[5] N.-H. Ding, J. J. Li, and L.-Q. Sun, "Molecular mechanisms and treatment of radiation-induced lung fibrosis," Current Drug Targets, vol. 14, no. 11, pp. 1347-1356, 2013.

[6] M. Reinfuss, A. Mucha-Małecka, T. Walasek et al., "Palliative thoracic radiotherapy in non-small cell lung cancer. An analysis of 1250 patients. Palliation of symptoms, tolerance and toxicity," Lung Cancer, vol. 71, no. 3, pp. 344-349, 2011.

[7] J. Bi and Y. Sun, "Investigation of Shen Fu injection on radioactive lung injury of patient with thoracic tumor radiotherapy," Hebei Journal of Traditional Chinese Medicine, vol. 37, no. 3, pp. 422-424, 2015.

[8] L. Cong, X. Wu, T. Liu, W. He, Y. Yang, and W. Cao, "Clinical research of radiation combined with elemene on non-small cell lung cancer of aged patients," Beijing Journal of Traditional Chinese Medicine, vol. 31, no. 11, pp. 821-823, 2012.

[9] X. Duan, W. Liu, and X. Xu, "Effect of Tan Re Qing injection on radiation-induced lung injury and expression of TGF- $\beta 1$," Journal of Tianjin University of Traditional Chinese Medicine, vol. 31, no. 1, pp. 13-15, 2014.

[10] Y.-L. Duan, X.-H. Fan, and J.-Q. Hou, "Clinical observation on effect of Aidi injection in treating radiation injury of lung," Chinese Journal of Integrated Traditional and Western Medicine, vol. 24, no. 3, pp. 256-257, 2004.

[11] W. Gong and X. Luo, "Clinical observation of integrative Chinese and Western medicine in treating radiation-induced lung injury," Hubei Journal of Traditional Chinese Medicine, vol. 31, no. 2, pp. 33-34, 2009.

[12] W. Hou, J. Liu, W.-G. Shi, and H.-S. Lin, "Multi-center, randomized, controlled clinical study of radiation pneumonitis treated with compound matrine injection in primary lung cancer patients," Chinese Journal of New Drugs, vol. 22, no. 17, pp. 2065-2068, 2013.

[13] Z. Huang, H. Li, and S. Z. Shuan Huang Lian, "Injection coordinate with Dan Xiang Injection in treating 32 cases of radiation-induced lung fibrosis," Shaanxi Journal of Traditional Chinese Medicine, vol. 27, no. 3, pp. 306-307, 2006.

[14] B. Li and X. Ma, "Observation of curative effect of Shenqi Fuzheng Injection on treatment and prevention from radiation pneumonia caused by chest radio therapy," Journal of Shanxi Medical College for Continuing Education, vol. 25, no. 5, pp. 5658, 2015.

[15] J. Li, B. Zou, Y. Wang, Y. Ruan, and H. Liu, "Study on the effect of Ligustrazine Injection on the level of TGF-Beta 1 in patients with lung injury radiation," Progress in Modern Biomedicine, vol. 16, no. 8, pp. 1494-1497, 2016.

[16] J. Li, R. Wang, H. Xiao, W. Wu, and Q. Zhang, "Clinical research of ligustrazine hydrochloride injection for prevention of radiation-induced lung injury," Modern Preventive Medicine, vol. 41, no. 18, pp. 3439-3442, 2014.

[17] G. Liu, Y. Zou, G. Liu, J. Bai, Y. Zhang, and X. Zhang, "Clinical observation of Lian-bi-zhi Injection and ultrasonic atomization for treatment of radiation pneumonitis," Hebei Medical Journal, vol. 35, no. 62, pp. 854-855, 2013.

[18] Y. Liu and J. Li, "Intervention effects of ligustrazine on radiation-induced lung injury in patients with thoracic malignancies," Pharmacology and Clinics of Chinese Materia Medica, vol. 32, no. 1, pp. 169-171, 2016.

[19] Y. Liu, H. Yu, C. Zhang et al., "Protective effects of berberine on radiation-induced lung injury via intercellular adhesion molecular-1 and transforming growth factor-beta-1 in patients with lung cancer," European Journal of Cancer, vol. 44, no. 16, pp. 2425-2432, 2008.

[20] X. Pan and Z. Tang, "Integrative of traditional Chinese and western medicine in treating radiation-induced lung injury: a report of 32 cases," Shanxi Journal of Traditional Chinese Medicine, vol. 22, no. 3, p. 28, 2006.

[21] Z. Ruan and L. Qun, "The efficacy of Danshen in the treatment of radiation pneumonitis," Zhejiang Medical Education, vol. 9, no. 2, pp. 47-48, 2010.

[22] C.-T. Tian, L.-Y. Han, and H.-L. Wang, "Tanreqing injection for radiation pneumonitis," Chinese Journal of Clinical Rehabilitation, vol. 10, no. 43, pp. 194-195, 2006.

[23] D. Xu, "Clinical effects of Xue Bi Jing Injection on early stage radiation pneumonitis in lung cancer patients," China's Rural Health, vol. 82, no. 4, pp. 21-31, 2016. 
[24] C. Xu, "Effects and nursing of Danshen Ligustrazine Injection on radiation pneumonitis," Lishizhen Medicine and Materia Medica Research, vol. 24, no. 7, pp. 1704-1705, 2013.

[25] Y. Xu, J. Liu, X. Wu, and W. Zheng, "Clinical study compound Kushen Injection combined phlegm hot clear prevention and treatment of acute radioactive pneumonia," China Journal of Chinese Medicine, vol. 28, no. 184, pp. 1273-1275, 2013.

[26] J. Wang, D. Guo, J.-Y. Wang et al., "Clinical research of alleviating radiation-induced lung injury and improving the quality of life by compound Kushen injection," Cancer Research and Clinic, vol. 25, no. 9, pp. 612-614, 2013.

[27] T. Wang, X. Feng, H. Wang, Y. Gad, Y. Zhang, and Y. Zhang, "Effect of cell lung Yangzhengxiaoji capsule in prevention of radiation pneumonitis for elderly patients with stage III non-small cell lung cancer," Chinese Journal of Difficult and Complicated Cases, vol. 43, no. 8, pp. 61-64, 2016.

[28] B. Yan and Z. Jiang, "Application of Shenmai Injection on prevention of radioactive pneumonia in patients with lung cancer," Shanxi Medical Journal, vol. 43, no. 8, pp. 895-896, 2014.

[29] J. Yang and Y. Jia, "Clinical observation of Shenmai Injection in adjuvant therapy of radioactive pneumonia," Journal of Emergency in Traditional Chinese Medicine, vol. 19, no. 7, p. 1134, 2010.

[30] X. Yang, H. Wang, F. Yang, H. Liu, T. Tian, and X. Zhang, "Effect of Tanreqing injection on lung cancer patients with radiation pneumonitis and radiation pulmonary fibrosis," Chinese Journal of Biochemical Pharmaceutics, vol. 35, no. 1, pp. 122-124, 2015.

[31] T. Zhang, S. Lin, J. Yue et al., "Clinical observation of Lian Bi Zhi Injection combined with Glucocorticoid and antibiotics in treating radiation pneumonitis," Journal of Clinical Pulmonary Medicine, vol. 12, no. 3, pp. 302-303, 2007.

[32] T. Zhang, B. Chen, X. Zhao, Z. Yu, T. Mao, and Y. Li, "Clinical research of attenuation effects Yiqi-Yangyin method in lung cancer radiotherapy," Traditional Chinese Medicine Journal, vol. 11, no. 5, pp. 52-55, 2012.

[33] W. Zheng, Z.-H. Gao, and L.-N. Wu, "Clinical observation on treatment of radiative pneumonia in patients with lung cancer by integrative Chinese and Western medicine," Chinese Journal of Integrated Traditional and Western Medicine, vol. 27, no. 12, pp. 1121-1123, 2007.

[34] Y. Zou and G. Liu, "Attenuation effects of Lian Bi Zhi Injection in treating radiative pneumonia," Modern Journal of Integrated Traditional Chinese and Western Medicine, vol. 17, no. 25, pp. 3932-3933, 2008.

[35] Z. S. Yan, Q. C. Wei, J. Li et al., "Experimental study on treating radiation pneumonitis by three kinds of different herbal injections," Western Journal of Traditional Chinese Medicine, vol. 27, no. 3, pp. 37-40, 2014.

[36] X.-R. Dong, J.-N. Wang, L. Liu et al., "Modulation of radiationinduced tumour necrosis factor- $\alpha$ and transforming growth factor $\beta 1$ expression in the lung tissue by Shengqi Fuzheng injection," Molecular Medicine Reports, vol. 3, no. 4, pp. 621-627, 2010.

[37] J. X. Li, Y. M. Zheng, X. Y. Hu et al., "Preventive and therapeutic effect of Aidi Injection on radiation-induced lung injury," Herald of Medicine, vol. 33, no. 2, pp. 184-188, 2014.

[38] Y. H. Sun, X. L. Yang, X. L. Ma et al., "Therapeutic effect on radioative lung injury by different doses of tanshinone II A microemulsion," Chinese Journal of Respiratory and Critical Care Medicine, vol. 15, no. 4, pp. 374-378, 2016.

[39] J. D. Cox, J. Stetz, and T. F. Pajak, "Toxicity criteria of the Radiation Therapy Oncology Group (RTOG) and the European organization for research and treatment of cancer (EORTC)," International Journal of Radiation Oncology, Biology, Physics, vol. 31, no. 5, pp. 1341-1346, 1995.

[40] Cancer Therpy Evaluation Program, Common Terminology Criteria for Adverse Events, Version 4.03, National Cancer Institute, 2010, https://evs.nci.nih.gov/ftp1/CTCAE/CTCAE_ 4.03_2010-06-14_QuickReference_5x7.pdf.

[41] W. B. Yin and X. Z. Gu, Radiation Oncology, Pecking Union Medical College Press, 4th edition, 2002.

[42] J. P. T. Higgins and S. Green, Cochrane Handbook for Systematic Reviews of Interventions Version 5.1.0, The Cochrane Collaboration, 2011, http://handbook.cochrane.org./.

[43] L. Wu, G. Wang, S. Liu et al., "Synthesis and biological evaluation of matrine derivatives containing benzo- $\alpha$-pyrone structure as potent anti-lung cancer agents," Scientific Reports, vol. 6, no. 1, Article ID 35918, 2016.

[44] Z. Qu, J. Cui, Y. Harata-Lee et al., "Identification of candidate anti-cancer molecular mechanisms of compound kushen injection using functional genomics," Oncotarget, vol. 7, no. 40, pp. 66003-66019, 2016.

[45] W. Wang, R.-L. You, W.-J. Qin et al., "Anti-tumor activities of active ingredients in Compound Kushen Injection," Acta Pharmacologica Sinica, vol. 36, no. 6, pp. 676-679, 2015.

[46] B. Yanju, L. Yang, B. Hua et al., "A systematic review and metaanalysis on the use of traditional Chinese medicine compound kushen injection for bone cancer pain," Supportive Care in Cancer, vol. 22, no. 3, pp. 825-836, 2014.

[47] J. Liu, Y. Wei, Q. Luo et al., "Baicalin attenuates inflammation in mice with OVA-induced asthma by inhibiting NF- $\kappa \mathrm{B}$ and suppressing CCR7/CCL19/CCL21," International Journal of Molecular Medicine, vol. 38, no. 5, pp. 1541-1548, 2016.

[48] C.-Y. Chen, W.-H. Peng, L.-C. Wu, C.-C. Wu, and S.-L. Hsu, "Luteolin ameliorates experimental lung fibrosis both in vivo and in vitro: implications for therapy of lung fibrosis," Journal of Agricultural and Food Chemistry, vol. 58, no. 22, pp. 1165311661,2010

[49] X. Pan, X. Cao, N. Li et al., "Forsythin inhibits lipopolysaccharide-induced inflammation by suppressing JAK-STAT and p38 MAPK signalings and ROS production," Inflammation Research, vol. 63, no. 7, pp. 597-608, 2014.

[50] S. Peng, J. Gao, W. Liu et al., "Andrographolide ameliorates OVA-induced lung injury in mice by suppressing ROSmediated NF- $\kappa$ B signaling and NLRP3 inflammasome activation," Oncotarget, vol. 7, no. 49, pp. 80262-80274, 2016.

[51] S. S. Jang, H. G. Kim, J. M. Han et al., "Modulation of radiationinduced alterations in oxidative stress and cytokine expression in lung tissue by panax ginseng extract," Phytotherapy Research, vol. 29, no. 2, pp. 201-209, 2015.

[52] L. Wang, X. Li, Y.-M. Song et al., "Ginsenoside Rg3 sensitizes human non-small cell lung cancer cells to $\gamma$-radiation by targeting the nuclear factor- $\kappa \mathrm{B}$ pathway," Molecular Medicine Reports, vol. 12, no. 1, pp. 609-614, 2015.

[53] M. Shahzad, A. Shabbir, K. Wojcikowski, H. Wohlmuth, and G. C. Gobe, "The antioxidant effects of radix astragali (Astragalus membranaceus and related species) in protecting tissues from injury and disease," Current Drug Targets, vol. 17, no. 12, pp. 13311340, 2016.

[54] E.-O. Kim, S. E. Kang, C. R. Im et al., "Tanshinone IIA induces TRAIL sensitization of human lung cancer cells through selective ER stress induction," International Journal of Oncology, vol. 48, no. 5, pp. 2205-2212, 2016. 
[55] Y. Jia, Z. Wang, A. Zang, S. Jiao, S. Chen, and Y. Fu, “Tetramethylpyrazine inhibits tumor growth of lung cancer through disrupting angiogenesis via BMP/Smad/Id-1 signaling," International Journal of Oncology, vol. 48, no. 5, pp. 2079-2086, 2016.

[56] J. Li, J. Yu, A. Liu, and Y. Wang, "Retraction notice to ' $\beta$-elemene against human lung cancer via up-regulation of P53 protein expression to promote the release of exosome': LUNG 86/2 (2014) 144-150," Lung Cancer, vol. 96, article 120, 2016.

[57] G. Li, B. Xie, X. Li et al., "Downregulation of peroxiredoxin-1 by $\beta$-elemene enhances the radiosensitivity of lung adenocarcinoma xenografts," Oncology Reports, vol. 33, no. 3, pp. 14271433, 2015. 


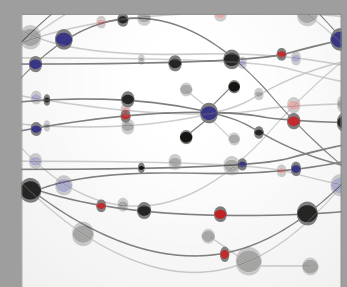

The Scientific World Journal
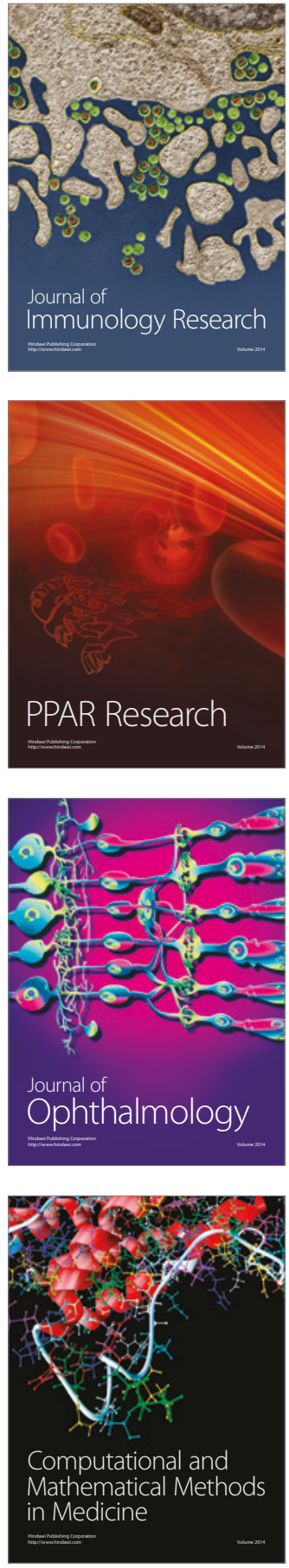

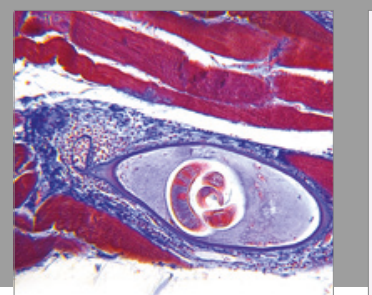

Gastroenterology Research and Practice
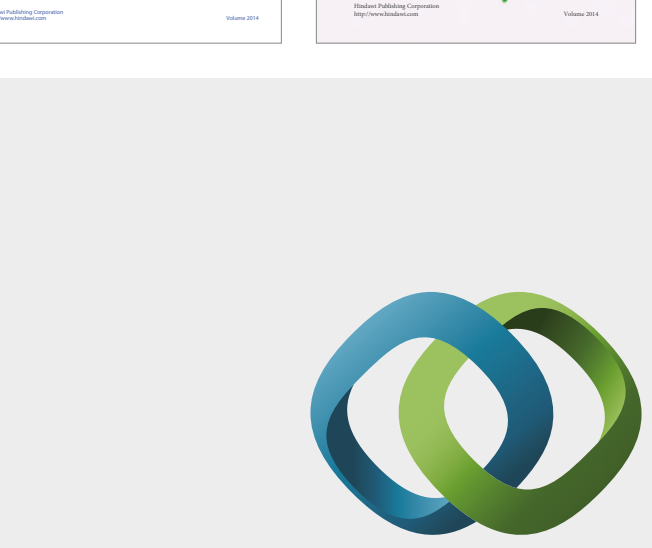

\section{Hindawi}

Submit your manuscripts at

https://www.hindawi.com
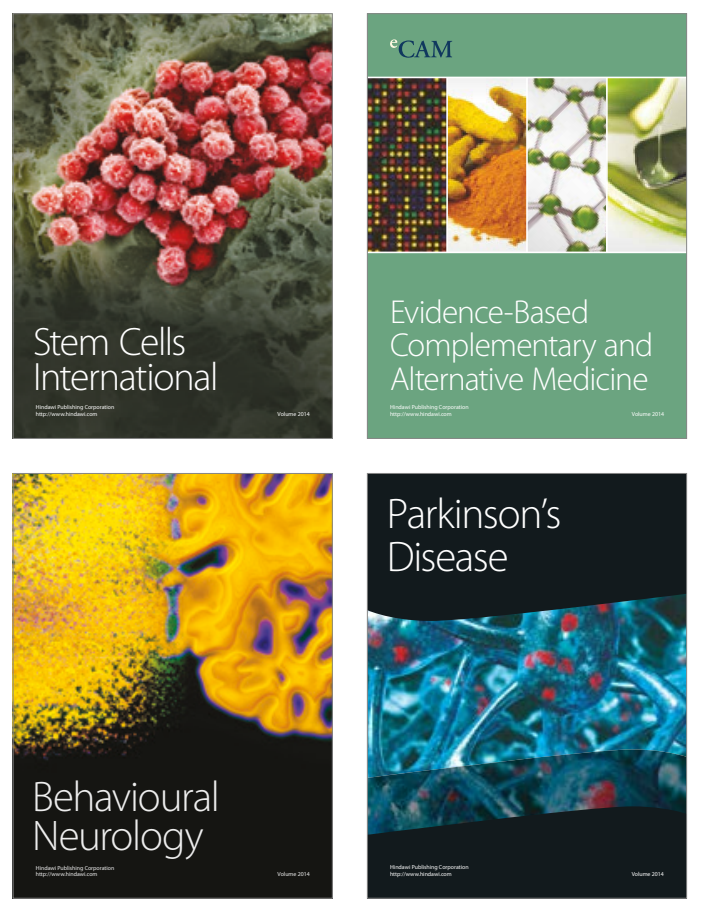
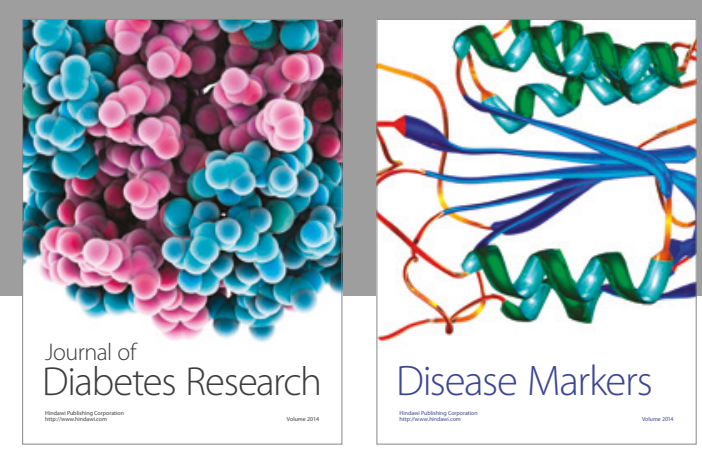

Disease Markers
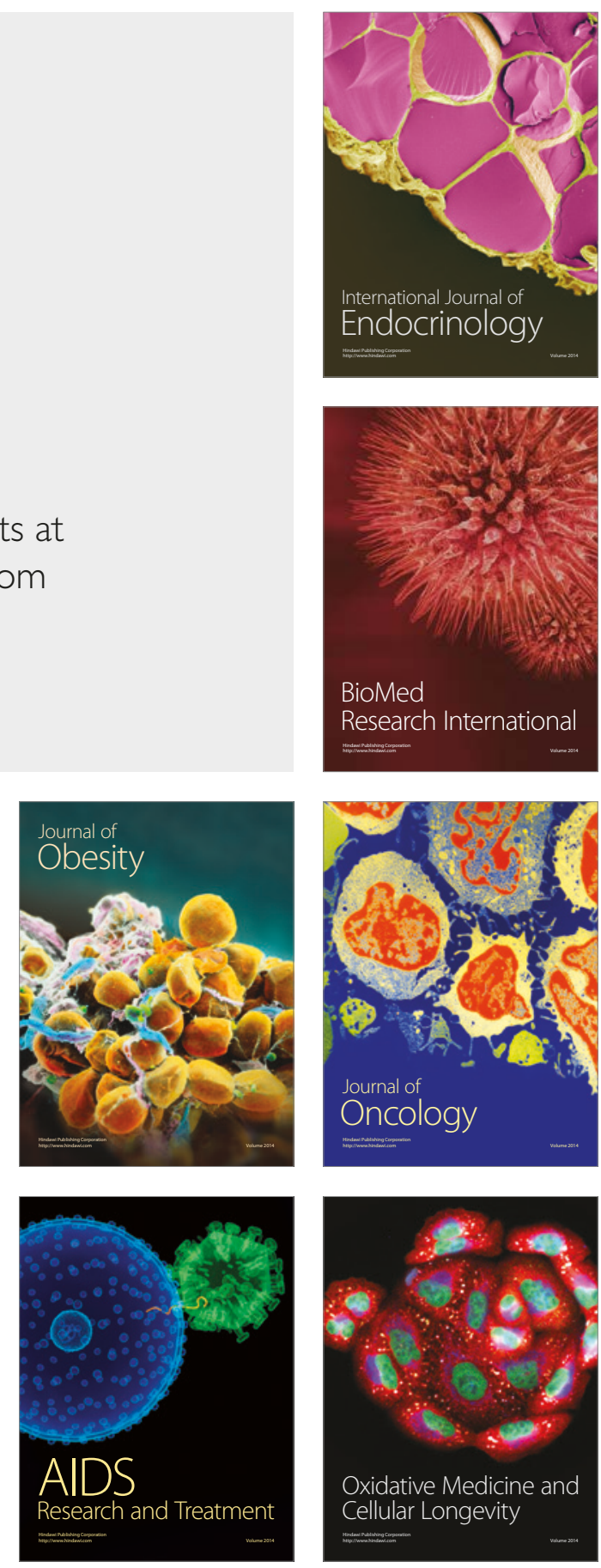